\title{
Effect Of Gender And Lifestyle Behaviors On BMI Trends In A Sample Of The First State's Undergraduate Population
}

Malcolm J. D’Souza, Wesley College, USA

Karri-Jo E. Walls, Wesley College, USA

Christine Rojas, Wesley College, USA

Lynn M. Everett, Wesley College, USA

Derald E. Wentzien, Wesley College, USA

\begin{abstract}
The 2010 Centers for Disease Control and Prevention (CDC) report indicates that 63.4\% of Delaware's adult population is overweight and $28 \%$ is obese. Here, the authors reveal analyses acquired from detailed investigations about the importance of gender, and other lifestyle factors and behaviors on the Body Mass Index (BMI) trends amongst an indiscriminate sample of the Wesley College (Wesley) undergraduate population. A 25-question paper-format survey was distributed to 307 randomly chosen Wesley undergraduates. The accrued qualitative (or categorical) data were transferred to an Excel spreadsheet to construct and observe frequency distributions. A Chi-square test of independence $\left(\chi^{2}\right)$ was performed between BMI status (normal, overweight, obese) and the following factors: gender, diet plan, adherence to the United States Department of Agriculture (USDA) MyPlate nutrition guide, use of the seasonal flu shot, weekly workout schedule, supplement usage, participation on athletic teams, questioning of label nutritional facts, and the use of added salt in food. A 2-sample proportion test was performed between students who were overweight or obese for the same factors. Also performed were t-tests for mean BMI for those who followed USDA MyPlate guidelines and for those who did not. An analysis of 278 completed surveys show that $29.5 \%$ of the Wesley respondents are overweight and $19.8 \%$ are obese. The mean BMI for males was statistically higher than the mean BMI for females. The mean BMI for students living on-campus was statistically higher than the mean BMI for students living off-campus. The results also demonstrate that adhering to the USDA dietary recommendations for fruit and dairy can be important factors in reducing the risk of obesity.
\end{abstract}

Keywords: Wesley College; CDC; AMA; BMI; USDA; Myplate; Delaware; Obese; Overweight; Undergraduate Research

\section{INTRODUCTION}

C n June 2013, in an effort to make the medical community and the US population more aware of the obesity epidemic, the American Medical Association (AMA) classified obesity as a new disease (Medical News Today, 2013). The Centers for Disease Control and Prevention (CDC), following World Health Organization (WHO) recommendations, labels an adult person as being obese if their Body Mass Index (BMI) ratio is greater than 30. BMI ranges between 25.0 and 29.9 are classified as being overweight and those between 18.5 and 24.9 and are said to be within a normal range. The CDC also considers adults whose BMI ratios fall below 18.5 to be underweight, and those whose ratios equal to or are greater than 40 are labeled morbidly obese. The WHO provided the global estimate of overweight adults to be $35 \%$ with $12 \%$ being classified as obese (WHO, 2014). The report on the Prevalence of Childhood and Adult Obesity in the United States (Ogden et al., 2014), estimated that $35.7 \%$ of the US adult population is obese. The WHO BMI data (WHO, 2014) is a cross-section of the world population as it was taken across all countries, so a comparison with the US data (Ogden et al., 2014) clearly demonstrates that obesity is decidedly prevalent in the US population. 
Rothman (2008) and others (Kravitz, 2010; Bhurosy and Jeewon, 2013; Ahima and Lazar, 2013) have communicated valid anthropometric interpretation flaws that can result when using the WHO recommended BMI scales as an adequate proxy for measuring the distribution of body fatness (or thinness). However, Himes (2009) and Lopez-Jimenez and Miranda (2010), have competently demonstrated that the current use of BMI scales to determine the prevalence of obesity in the various populations is clinically adequate and appropriate. Furthermore Ogden, Carroll, and Flegal (2008), and Himes (2009), stressed that BMI ratios due to their simplicity are relevant and important as an overweight and obesity indicator especially in the study of children and adolescents. In 2011, the WHO did recommend that where possible, abdominal obesity should also be measured and used in conjunction with BMI to assess and accurately predict disease risk (WHO, 2011).

Ogden et al. (2014) in the Prevalence of Childhood and Adult Obesity in the United States reported on a large-scale sample of the US non-institutionalized population where Hispanics, non-Hispanic blacks, and nonHispanic Asians were oversampled. According to the BMI cutoffs based on the weight and height measurements of 9120 participants, they concluded that there have been no significant changes in obesity prevalence in youth or adults between 2003-2004 and 2011-2012.

In Delaware, the pervasiveness of childhood, adolescent, and adult obesity is a major public health concern and a substantial drain on health care resources (Delaware News Journal, September 6, 2014). In 2010, CDC data (CDC Trends by State, 2010) on the First State reported that $63.4 \%$ of all resident adults above the age of 18 were overweight, and $28 \%$ were obese. The data further showed that only $27.7 \%$ of Delaware's adult population consumed three or more servings of vegetables daily, and $21.9 \%$ of all adults reported no integration of any physical activity during an entire month. A decade ago, the adult Medicare and Medicaid obesity-attributable medical expenditures for the State were shown to be 10 and 14\% respectively (Finkelstein, Fiebelkorn, and Wang, 2004). Health care currently consumes $17 \%$ of the State's budget on Medicaid alone which is $5 \%$ above the national average (Centers for Medicaid and Medicare Services, 2011). In March 2014, Gallup announced that Delaware is the third fattest state in the US with 34.3\% of its population classified as being obese (Gallup Well-Being, 2014). Additionally a relatively recent statewide study (Gupta, 2014) chronicled obesity to be a major independent risk factor both for diabetes and cardiovascular disease.

The Nemours Health and Prevention Services (Chang et al., 2010) showed that approximately 37 percent of Delaware's children were overweight or obese. Amongst Delaware's obese and overweight adolescents, there was a strong association between accurate perception of weight, intention to lose the weight, and action taken to change weight (Fagan et al., 2008). Nonetheless, a statewide public opinion poll (Sweetman, Sherretz, and Ackerman, 2007) showed that $41 \%$ of Delaware parents were not really worried about childhood obesity. This minimal concern is in all probability due to national and international reports showing weak correlations between obesity and academic achievement (Taras and Potts-Datema, 2005; MacCann and Roberts, 2013). However, a longitudinal study over 12 years of 91,798 female nurses indicated that childhood-adolescence obesity is a strong and independent risk factor for adult depression (Sanchez-Villegas et al., 2013). As a result of such thoughtful local, national, and international findings, Delaware has now initiated regulations to combat the rise in childhood obesity by attacking it through increasing fitness levels in elementary school children (Raymond, 2013) and through the implementation of nutrition interventions in child-care settings (Lessard, Leng, and Brennan, 2013).

In 2004, the burden of college campus obesity increased from 12\% in 1991 to 36\% (LaCaille et al., 2011). National concern about obesity on campus (Sparling, 2007) has identified probable causes to include campus culture (Cash and Green, 1986; Betz et al., 1994; Brener and Gowda, 2001; Costin, 2013), diet and exercise (Haberman and Luffey, 1998), gender (Hoerr et al., 2002), college standing (Driskel, Kim, and Goebel, 2005), demographics (James and Bonds, 2006; Sira and Pawlak, 2010; Wang and Beydoun, 2007), stress (Torres and Nowson, 2007), living arrangements (Brunt and Rhee, 2008), and student nutritional knowledge and attitudes (Wansink and Payne, 2008; Dissen et al., 2011). Although behavior, environment, and family history (Ellis and Haman, 2004) do play a role in obesity, studies consistently show that consuming too many calories and not getting enough physical activity is still the main leading cause of obesity in the US population (US Dept. of Health, 1996). The College Health and Nutrition Assessment Survey (CHANAS) at the University of New Hampshire (UNH) using polling data from 1,384 students (Morrell, Reilly, and Carey, 2013) showed that $25.1 \%$ of their students were overweight and $4.5 \%$ fell in the obese category. Moreover, Kang et al. (2014) found that low fruit/vegetable intake and physical inactivity were 
common among all 30,093 US college students surveyed and that the overweight/obesity categories appeared to cluster differentially amongst the races.

Puhl and Heuer (2009) after a systematic literature search found that obese individuals in general were highly stigmatized and faced multiple forms of prejudice and discrimination. Amongst the US undergraduate population, Brunson et al. (2014) provided substantial evidence that weight-related social pressures are associated with a variety of negative health and well-being outcomes, particularly for women.

To conquer detrimental physiological and psychological outcomes associated with obesity, a number of novel encouraging interventions using social media tools to promote behavioral change (Napolitano, 2013; Hansen, 2013) are being introduced to influence students to be more active and to pay closer attention to their dietary intake. Such interventions for college students are especially important in Delaware, as a Delaware State University (DSU) assessment of fitness study (Grimes, Jackson, and Shorter, 2013) indicated that half of its student participants were overweight or obese and that women were more likely to be obese when compared to men. At DSU, $62 \%$ of the undergraduates are female.

To moderate adverse health effects due to the nation's obesity epidemic, the United States Department of Agriculture (USDA) created the MyPlate nutrition guide in 2010 so that Americans can easily meet the recommended nutritional goals (Britten et al., 2012). Recent data obtained (Baker, 2013) from a 30-question online survey of 564 undergraduates at the University of Delaware (UD) showed that its students preferred the new MyPlate icon to the former USDA MyPyramid icon. This study also indicated that the UD undergraduates were intent on assimilating further information about the MyPlate program as they found it valuable and applicable.

To analyze current BMI trends in a sample of Delaware's college student population and to determine if these students are following the MyPlate guidelines, this project focused on the eating habits of undergraduates at Wesley College (Wesley). We looked for associations between BMI and gender, food choices, physical activity, nutritional knowledge, supplement usage, lifestyle factors, and weight gain.

Wesley is a private baccalaureate minority-serving institution (MSI) in Delaware. Its 2013 student population of 1,600 had minorities comprising $47 \%$ of its total enrollment (39\% African-American, 43\% Caucasian, $5 \%$ Hispanic, $3 \%$ Biracial, $1 \%$ Asian, and 2\% other). Females comprised 52\% of the total Wesley undergraduate population.

\section{METHODS}

The College's Institutional Review Board (IRB) approved this research project that began in the 2013 spring semester. A 25-question survey was distributed to 307 Wesley students. Each participant was asked to sign a consent form which introduced this study, explained its purposes and methods, and outlined any perceived risks and benefits of participating in such a survey. All signed consent forms were stored in a sealed envelope while the study was being completed; then once complete, the consent forms were shredded. All surveys were completed anonymously and were kept in a secure location. Distribution of the surveys began in April of 2013 and ended in August 2013. A copy of the survey is attached as Appendix A.

The surveys were randomly distributed throughout campus to ensure that there was variety in age, gender, and major field of college study. Locations for handing out survey-forms included the College Center, library, cafeteria, dining hall, and the survey was also administered in a few class rooms. Once all 307 surveys were returned, each survey was transferred by hand onto an Excel sheet. The BMI ratios for all participants were calculated using their self-reported height and weight and the CDC's BMI calculator. Once all BMIs were calculated, they were categorized using the CDC standard weight status categories into four groups; underweight, normal, overweight, and obese. The percentage of Wesley students who were at a normal weight according to the standard weight status categories associated for BMI ranges for adults was determined by creating pivot charts in Excel. Three statistical tests were performed to analyze the relationship between lifestyle factors and BMI status. The tests included the Chi-square test for independence $\left(\chi^{2}\right)$, the 2-sample proportion test, and the $t$-test for mean BMI. An alpha level of 5\% was used to indicate a statistically significant difference for the hypothesis tests. 
A Chi-square test of independence $\left(\chi^{2}\right)$ was performed between BMI status (normal, overweight, obese) and the following factors: gender (male, female), diet plan (yes, no), adherence to the USDA MyPlate nutrition guide (yes, no), use of the seasonal flu shot (yes, no), weekly workout schedule (0-2, 3-4, 5+), supplement usage (yes, no), participation in athletic teams (yes, no), reading of the information posted on nutritional labels (yes, no), and the use of added salt in food (yes, no). An alpha level of 5\% was used to test for a relationship between variable 1 (BMI status) and variable 2 (the other factors each tested separately).

A $t$-test for mean BMI was also performed between groups of students. A right-tail test $\left(H_{a}: \mu_{1}>\mu_{2}\right)$ was performed for gender (male vs. female), residency (living on-campus vs. living off-campus), protein consumption (following USDA MyPlate guidelines vs. not following USDA MyPlate guidelines), and vegetable consumption (following USDA MyPlate guidelines vs. not following USDA MyPlate guidelines). A left-tail test $\left(H_{a}: \mu_{1}>\mu_{2}\right)$ was performed for the major (science vs. other majors), fruit consumption (following USDA MyPlate guidelines vs. not following USDA guidelines), and dairy consumption (following USDA MyPlate guidelines vs. not following USDA MyPlate guidelines). An alpha level of 5\% was used to test for a significant difference between the mean BMI.

A 2-sample proportion test was also performed between students who were overweight or obese for the same factors. A right-tail test $\left(H_{a}: \mu_{1}>\mu_{2}\right)$ was performed for students who followed the USDA MyPlate guidelines (sample 1) and for those who did not (sample 2) for recommended protein consumption and vegetable consumption. A left-tail test $\left(H_{a}: \mu_{1}<\mu_{2}\right)$ was performed for students who did not follow the USDA MyPlate guidelines (sample 1) and for those who did follow the guidelines (sample 2). An alpha level of 5\% was used to test for a significant difference between the proportions.

\section{RESULTS AND DISCUSSION}

Respondents returned 300 usable surveys which represents a fifth of the total student body. Of the 300 surveys, $63 \%$ were females and $76 \%$ were students between the ages 18 and 21 . Respondents included $34 \%$ freshman, $29 \%$ sophomores, and $37 \%$ classified themselves as juniors and/or seniors. Approximately $66 \%$ of the respondents lived on-campus and $34 \%$ lived off-campus. The mean BMI, weight, and height of the students in the sample were $25.5 \pm 5.1 \mathrm{lbs} . /$ in. $^{2}, 164.8 \pm 42.0 \mathrm{lbs}$., and $67.2 \pm 4.2 \mathrm{in}$. respectively. According to the BMI categories, 12 respondents (4\%) were classified as being underweight and as this sample size was too small to provide useful statistical information, these surveys were not used in any further statistical analyses. Ten other surveys with incomplete data were also removed from the sample.

In Figure 1, of the remaining 278 student participants, 50.7\% of the undergraduates were within the normal weight range, $29.5 \%$ were overweight and $19.8 \%$ were classified as being obese. Amongst the obese classification, five had a BMI ratio that was greater than 40 which identifies them as being morbidly obese. The results show that a fifth of the Wesley students surveyed are obese. With more than three-quarters saying that they are under the age of 21 , this study identifies the existence of an on-campus obesogenic environment. The detailed statistical analyses of the associations observed between BMI and student lifestyle factors and behaviors are shown in Table 1. 


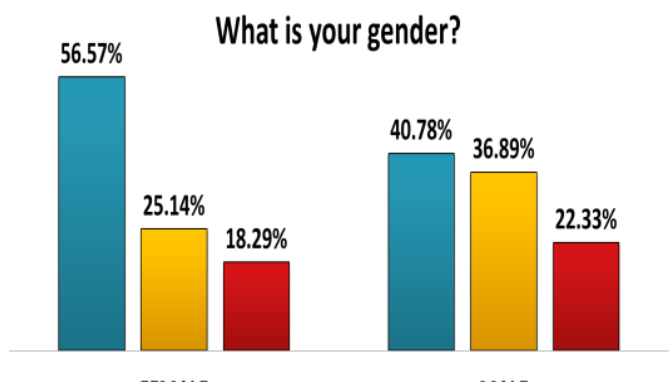

FEMALE

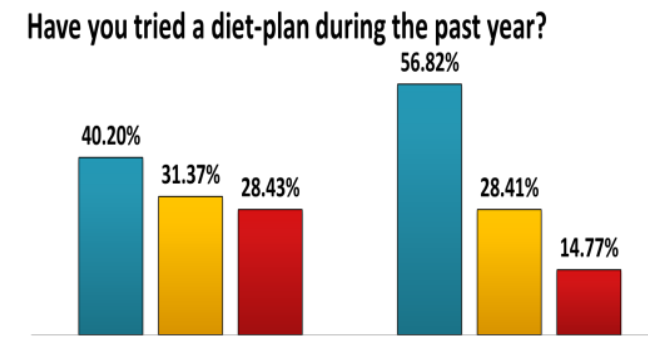

YES
NO

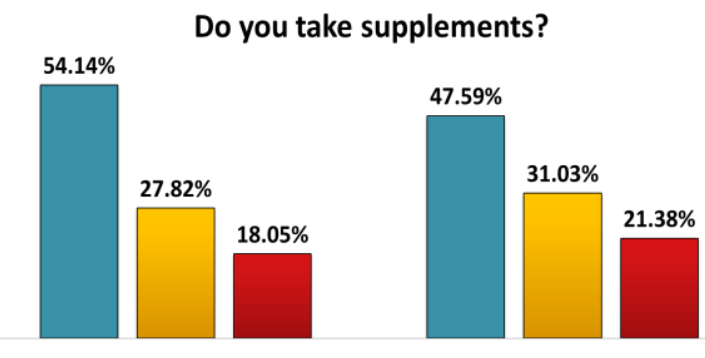

YES

NO

Does nutritional information on food labeling in the grocery store influence your purchase?

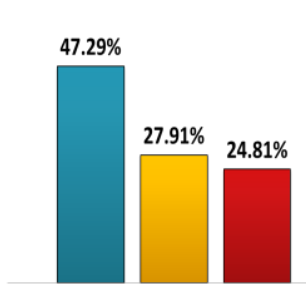

YES

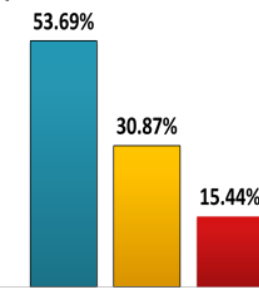

No

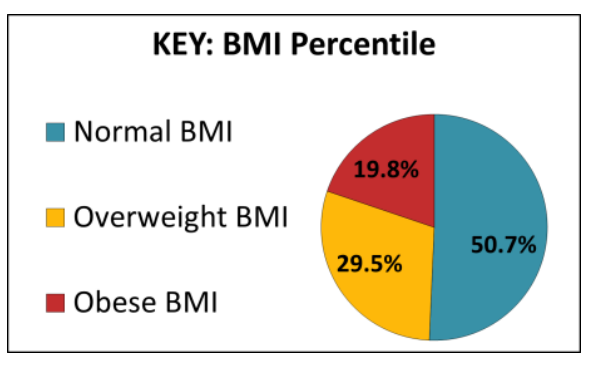

How often do you excercise for more than $\mathbf{3 0}$ minutes at a time (per week)?

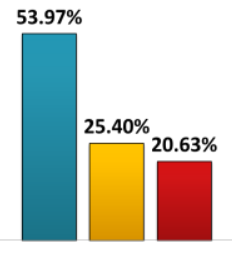

0 Tо 2

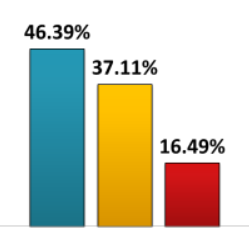

3 OR 4

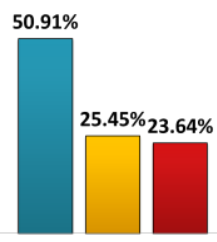

$>5$

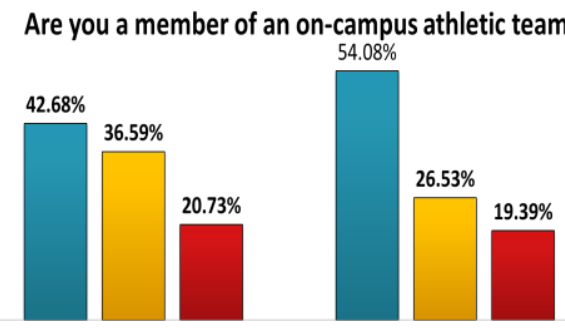

YES
No
Did you get a flu shot during the past year? $57.25 \%$

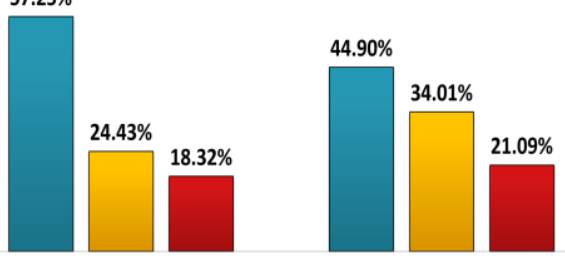

YES

NO

Figure 1. Effect of Gender, Demographics, and Lifestyle Behaviors on BMI Trends

Do you add salt to your food at the table?

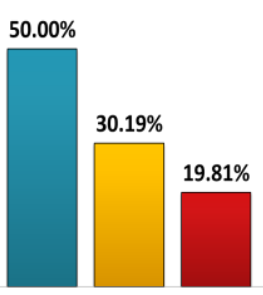

YeS

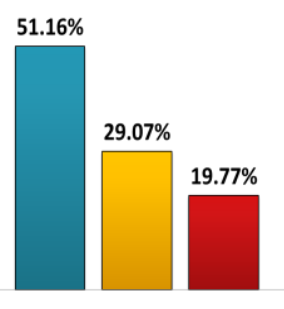

No 
Table 1 shows the results of the Chi-square test for independence $\left(\chi^{2}\right)$. Statistically significant results at a $5 \%$ alpha level were found between BMI status and gender (p-value $=0.034$ ) and between BMI status and diet plan $(\mathrm{p}$-value $=0.007)$. The results also showed that a greater percentage of students who tried a diet-plan in the past $(59.8 \%)$ were overweight or obese than the percentage of students who did not try a diet-plan in the past (43.2\%). The difference is statistically significant. Body-image can force undergraduates to try a diet-plan but this often does not automatically result in weight loss or help in the continued maintenance of weight control (Costin, 2013).

Statistically significant results for independence were not found between BMI status and the seasonal flu shot, exercise during the week, supplement usage, athletic team members, reading of the information posted on nutritional labels, and the use of added salt in food.

Table 1. Chi-Square Test For Independence

\begin{tabular}{lcc}
\hline \multicolumn{1}{c}{ Variable 2 } & $\mathbf{H}_{\mathbf{a}}:$ BMI Status (Variable 1)And Variable 2 Are Dependent & p-value \\
\hline Athletic team member & $\chi^{2}$ & 0.172 \\
Supplement usage & 3.515 & 0.500 \\
Exercise during week & 1.348 & 0.337 \\
Nutrition label & 4.540 & 0.147 \\
Salt in food & 3.843 & 0.977 \\
Flu shot & 0.045 & 0.104 \\
Diet plan & 4.511 & 0.007 \\
Gender & 9.799 & 0.034 \\
\hline
\end{tabular}

Table 2 shows the results of the $t$-test for the mean BMI. Statistically significant results at a $5 \%$ alpha level for the right-tail tests were found for gender ( $\mathrm{p}$-value $=0.001)$, residency ( $\mathrm{p}$-value $=0.009$ ), and following the USDA MyPlate guidelines for protein ( $\mathrm{p}$-value $=0.001)$ consumption. The mean BMI for males $(26.8 \mathrm{lbs}$.) was statistically higher than the mean BMI for females $(24.8 \mathrm{lbs}$.). The mean BMI for students living on-campus (26.0 lbs.) was statistically higher than the mean BMI for students living off-campus (24.8 lbs.). The mean BMI for students who followed the guidelines for protein consumption (26.5 lbs.) was statistically higher than the mean BMI for students who did not $(24.6 \mathrm{lbs}$.). Statistically significant results at a $5 \%$ alpha level for the left-tail tests were found for following the USDA MyPlate guidelines for fruit consumption ( $\mathrm{p}$-value $=0.03$ ) and following the USDA MyPlate guidelines for dairy consumption ( $\mathrm{p}$-value $=0.006$ ). The mean BMI for students who followed the USDA MyPlate guidelines for fruit consumption (25.0 lbs.) was statistically lower than the students who did not (26.1 lbs.). The mean BMI for students who followed the USDA MyPlate guidelines for dairy consumption (24.1 lbs.) was statistically lower than the students who did not (25.8 lbs.). 
Table 2. $t$-test For Mean BMI

\begin{tabular}{|c|c|c|c|c|}
\hline \multicolumn{5}{|c|}{ 2a: $H_{a}: \mu_{1}>\mu_{2}$} \\
\hline Item & Mean BMI (lbs/in2) & Mean BMI (lbs/in2) & t-stat & p-value \\
\hline Gender & Male (26.8) & Female (24.8) & 3.29 & 0.001 \\
\hline Residence & On-campus (26.0) & Off-campus (24.6) & 2.35 & 0.009 \\
\hline \multicolumn{5}{|c|}{ 2b: $H_{a}: \mu_{1}<\mu_{2}$} \\
\hline Item & Mean BMI (lbs/in2) & Mean BMI (lbs/in2) & t-stat & p-value \\
\hline Major & Science major (24.9) & Other majors (25.8) & -1.43 & 0.070 \\
\hline \multicolumn{5}{|c|}{ 2c: $H_{a}: \mu_{1}>\mu_{2}$} \\
\hline Item & Mean BMI (lbs/in²) & Mean BMI (lbs/in²) & t-stat & p-value \\
\hline Protein & Following (26.5) & Not following (24.6) & 3.23 & 0.001 \\
\hline Vegetable & Following (25.4) & Not following (25.3) & 0.10 & 0.450 \\
\hline \multicolumn{5}{|c|}{ 2d: $H_{a}: \mu_{1}<\mu_{2}$} \\
\hline & Mean BMI (lbs/in²) & Mean BMI (lbs/in $\left.{ }^{2}\right)$ & t-stat & p-value \\
\hline Fruit & Following (25.0) & Not following (26.1) & -1.85 & 0.030 \\
\hline Dairy & Following (24.1) & Not following (25.8) & -2.52 & 0.006 \\
\hline
\end{tabular}

Tables 3 and 4 show the results of the 2-sample proportion test performed between students who were overweight or obese for the following factors: adherence to the USDA MyPlate nutrition guidelines, gender, use of the seasonal flu shot, trying a diet plan, use of supplements, reading the information posted on nutritional labels, participation in athletic teams, and the use of added salt in food. Statistically significant results at a 5\% alpha level for the right-tail 2-proportion tests were found for gender $(\mathrm{p}$-value $=0.004)$ and the use of the flu shot $(\mathrm{p}$-value $=$ 0.020). A statistically greater percentage of males were overweight or obese (59\%) than females (43\%). A statistically greater percentage of students who did not get a flu shot were overweight or obese (55\%) than students who did get a flu shot (43\%). Statistically significant results at a 5\% alpha level for the left-tail proportion tests were found for students who followed the USDA MyPlate guidelines for fruit consumption ( $\mathrm{p}$-value $=0.04$ ), diet plan (pvalue $=0.004)$, and athletic participation ( $\mathrm{p}$-value $=0.042)$. A statistically lower percentage of students who followed the USDA MyPlate guidelines for fruit consumption were overweight or obese (43\%) than students who did not follow the guidelines (52\%). A statistically lower percentage of students who did not try a diet plan were overweight or obese $(43 \%)$ than the students who did try a diet plan $(60 \%)$. A statistically lower percentage of students who were not athletes were overweight or obese $(46 \%)$ than students who were athletes $(57 \%)$.

Table 3. Z-Test For The Difference Between The Proportion Overweight Or Obese

\begin{tabular}{lcccc}
\hline & & 3a: $H_{a}: p_{1}>p_{2}$ & p-value \\
\hline Item & Following & Not Following & Z-stat & 0.10 \\
Protein & $57 \%$ & $40 \%$ & 2.94 & 0.80 \\
Vegetable & $50 \%$ & $46 \%$ & 0.84 & p-value \\
\hline & & & & 0.04 \\
\hline Item & Following & Not Following $H_{a}: p_{1}<p_{2}$ & 0.05 \\
Fruit & $43 \%$ & $52 \%$ & -1.68 & -1.61 \\
\hline
\end{tabular}


Table 4. Z-Test For The Difference Between The Proportion Overweight Or Obese

\begin{tabular}{|c|c|c|c|c|}
\hline \multicolumn{5}{|c|}{ 4a: $H_{a}: p_{1}>p_{2}$} \\
\hline Item & Sample 1 & Sample 2 & Z-stat & p-value \\
\hline Gender & Male $(59 \%)$ & Female $(43 \%)$ & 2.544 & 0.006 \\
\hline Flu shot & No $(55 \%)$ & Yes $(43 \%)$ & 2.057 & 0.020 \\
\hline \multicolumn{5}{|c|}{ 4b: $H_{a}: p_{1}<p_{2}$} \\
\hline Item & Sample 1 & Sample 2 & Z-stat & p-value \\
\hline Diet plan & No $(43 \%)$ & Yes $(60 \%)$ & -2.672 & 0.004 \\
\hline Supplement & No $(46 \%)$ & Yes $(51 \%)$ & -1.091 & 0.138 \\
\hline Nutrition label & No $(46 \%)$ & Yes $(53 \%)$ & -1.065 & 0.143 \\
\hline Athletic team member & No $(46 \%)$ & Yes $(57 \%)$ & -1.734 & 0.042 \\
\hline Salt in food & No $(49 \%)$ & Yes $(50 \%)$ & -0.188 & 0.425 \\
\hline
\end{tabular}

\section{CONCLUSIONS}

The main goals of this study were to assess the impact that lifestyle factors and behaviors of Wesley's undergraduate population had on their BMI. Two decades ago (Haberman and Luffey, 1998) at the University of Pittsburg (Pitt), $80 \%$ of undergraduate males were shown to have a normal BMI; the Wesley results show that only $41 \%$ of men are within a normal BMI range. For women in the same 1998 Pitt study, $90 \%$ were reported to have a normal BMI. At Wesley, the results show that only $57 \%$ of females are within a normal BMI range.

A decade later in 2008, Brunt and Rhee showed that the obesity rate of college students where $75 \%$ of respondents were 21 years of age or younger (very similar to the Wesley cohort) had 35\% classified as overweight or obese. This study now shows that the higher body weight percentile is continually increasing, with $49 \%$ of the Wesley students said to be overweight or obese. In addition, Brunt and Rhee (2008) found that $60 \%$ of their surveyrespondents living off campus were more likely to be overweight or obese. In contrast, this study shows that $66 \%$ of the Wesley respondents living on campus were more likely to be overweight or obese. On-campus students rely on the Wesley College cafeteria which has a buffet-style arrangement. Hence, the greater than normal BMI for students living on-campus affirms prior associations (Wansink and Payne, 2008; Dissen et al., 2011) exhibited by buffet patrons.

A further comparison to the more recent UNH data (Morrell, Reilly, and Carey, 2013) suggests that the Wesley statistics regarding obesity-trends associated with the Delaware student-body are very different from other groups of undergraduates residing on campuses along the East Coast. The Wesley analyses do indicate that students who follow the USDA guidelines for recommended daily portions of fruit and dairy do have a lower BMI than those who do not. Also consistent with the observations made by Kang et al. (2014), more than half of the Wesley students surveyed are not consuming the recommended daily portions of fruit, dairy, protein, and vegetables. Only $46 \%$ consume recommended daily portions of fruit, and $21 \%$ consume the recommended daily portions of dairy.

The Wesley College authors found that students who followed the USDA guidelines (5-6 oz.) for recommended daily portions of protein (meat, beans, eggs, nuts, etc) have a higher BMI. One possible explanation for this observation would be that some respondents such as competitive athletes are increasing their intake of protein to build muscle mass, and since muscle weighs more than fat their BMI value would be skewed. This was found to be indeed true, as $57 \%$ of those who identified themselves as athletes had higher than normal BMI ratios. Overall, $23 \%$ of the students reported a greater than recommended daily consumption of protein (excluding dairy) and $45 \%$ of males consumed more than the daily recommended $6 \mathrm{oz}$. of protein (meat, beans, eggs, nuts, etc).

In general at Wesley, $59 \%$ of the men and $43 \%$ of the females surveyed are overweight or obese. In addition, males have a higher BMI value than females. This observation is diametrically opposite to a recent DSU study (Grimes, Jackson, and Shorter, 2013) which found that a greater number of females were overweight or obese. DSU is a Historically Black College and University (HBCU) where $72 \%$ of the undergraduates are AfricanAmerican, 5\% Hispanic, 1\% Asian, 4\% Biracial, 5\% International, and 2\% of the population did not report their race. The underrepresented undergraduate population at Wesley is $47 \%$. Studies have proved that female obesity is very dependent on race and ethnicity, and that obesity is prevalent in African-Americans and Hispanic women 
(James and Bonds, 2006; Sira and Pawlak, 2010; Kang et al., 2014; Wang and Beydoun, 2014). Interestingly, amongst college students, it was also shown (Betz et al. 1994) that females underreported their self-reported weight to a greater degree.

Students expressing healthy preventive behaviors such as getting a seasonal flu shot had lower BMI ratios. STEM majors also had lower mean BMI scores in comparison to students enrolled in other fields. Possible explanations include forced non-sedentary behaviors as a result of science laboratory classes and courses that incorporate field-activity. Additionally, there are class-based interventions where science courses deliver nutritioneducation and interventions consisting of education on web-based fitness apps.

The Wesley findings clearly demonstrate significant differences between dietary consumption and BMI values; therefore, preventive interventions are needed to help the typical Wesley College student make healthier dietary decisions. This study asserts that campus culture plays an important role in the obesity puzzle and perceptions and behavior relating to obesity can be modulated on-campus. In fall 2014, the College implemented a new core-curriculum. In this new core, all freshmen are required to enroll in a First-Year Seminar (FYS) course and a Frontiers in Science course. One of us (Everett) will teach an FYS course on Diabetes. In this course, students will identify links between lifestyle choices and the development of Type 2 diabetes, investigate the impact on the diabetic individual and the health care system, conduct a personal health assessment, and develop a life plan for healthful living.

The main limitation of this Wesley project is the collection of self-reported data which is subject to a variety of errors. Students may have inaccurately reported their daily consumptions of fruit, dairy, protein, and vegetables. Therefore, the data represented may be more or less than their actual daily dietary consumption. Another limitation may be the method used to determine BMI values. Using the self-reported height and weight of the respondent can be misleading because students who participate in strength training, such as athletes do, may be classified as overweight or obese yet may have a greater lean body mass than is estimated by BMI. An ideal way to measure body fat is with fat calipers. This hand-held device quickly and easily measures the thickness of a fold in the skin with its underlying layer of fat and can estimate the total percent of body fat within the person's entire body. Continued analysis of the BMI trends of the Wesley College student population is needed to determine the health risks.

\section{ACKNOWLEDGEMENTS}

The Wesley College Directed Research Program (D'Souza et al. 2011, D'Souza and Wang 2012) is supported through Federal and State awards. The authors acknowledge support from an Institutional Development Award (IDeA) from the National Institute of General Medical Sciences (NIGMS) at the National Institutes of Health (NIH grant no. P20GM103446, Delaware INBRE program); a National Science Foundation (NSF) Experimental Program to Stimulate Competitive Research grant (Delaware EPSCoR program); an NSF ARI-R2 grant 0960503; an NSF SSTEM grant 1355554; and the State of Delaware (The Delaware Economic Development Office). The DE-INBRE and DE-EPSCoR grants were obtained through the leadership of the University of Delaware and the authors sincerely appreciate their efforts.

\section{AUTHOR INFORMATION}

Malcolm J. D'Souza is professor of chemistry at Wesley College, in Dover, Delaware. He is the principal investigator on the Wesley College DE-INBRE, DE-EPSCoR, NSF ARRA, and Cannon Scholar (NSF S-STEM) programs. Dr. D’Souza also serves as the Associate Dean of Interdisciplinary/Collaborative Sponsored Research. In 2009, he was nominated and identified by a selection committee for the 2009 Northern Illinois University (NIU) Golden Anniversary Alumni Award. In 2012, he was awarded the American Chemical Society's (ACS) E. Emmett Reid Award, which recognizes high-quality teaching in chemistry at small colleges in the ACS Mid-Atlantic region. In addition to his research in physical organic chemistry, he also has projects, presentations, and publications in the area of chemometrics, weight-loss studies, and in the design of commercial databases that assist in the development of new pharmaceutical and agricultural products. E-mail: malcolm.dsouza@ wesley.edu (Corresponding author) 
Karri-Jo E. Walls is a senior in the biology program at Wesley College. She completed this year long project to fulfill her senior-thesis requirement. In February 2014, Karri-Jo presented her work as a poster at the American Association for the Advancement of Science (AAAS) Annual Meeting in Chicago, IL. In June 2014, this research was competitively selected to be showcased by the Epidemiology \& Public Health Division in a special highlighted session at the $5^{\text {th }}$ Biennial National IDeA Symposium of Biomedical Research Excellence (NISBRE) conference, in Washington, D.C. Email: karri-jo.walls@email.wesley.edu

Christine Rojas is a junior in the biology program at Wesley College. Her participation in this undergraduate research project was sponsored through a 2013 NIH-NIGMS Delaware INBRE summer internship program at Wesley College. In August 2013, Christine presented a poster at the $5^{\text {th }}$ Northeast IDeA Regional Conference, at the University of Delaware. Email: christine.rojas@email.wesley.edu

Lynn M. Everett is an professor of biology at Wesley College. She received her Ph.D. in Physiology from Indiana University Graduate School in Indianapolis, IN. She has taught anatomy and physiology courses for 14 years to undergraduate students in the allied health fields. She has also taught the department's capstone research course and currently serves as a mentor on independent senior research projects. E-mail: lynn.everett@wesley.edu

Derald E. Wentzien is professor of mathematics at Wesley College. He received his Ph.D. in Operations Research from the University of Delaware. He has taught undergraduate probability and statistics courses at Wesley College. He has also mentored undergraduate research projects including some sponsored by the DE-INBRE, DE-EPSCoR, and NASA Delaware Space Grant programs. E-mail: derald.wentzien@wesley.edu

\section{REFERENCES}

Ahima R.S., Lazar, M.A. (2013). Physiology: The Health risk of Obesity—Better Metrics Imperative. Science, 341(6148), 856-858.

Baker, S.D. (2013). Guidelines for Promoting MyPlate and its Website Among College Students. Doctoral dissertation, University of Delaware.

Betz, N.E., Mintz, L., and Speakmon, G. (1994). Gender Differences in the Accuracy of Self-Reported Weight. Sex Roles, 30(7-8), 543-552.

Bhurosy, T., and Jeewon, R. (2013). Pitfalls of Using Body Mass Index (BMI) in Assessment of Obesity Risk. Current Research in Nutrition and Food Science Journal, 1(1), 71-76.

Brener, N.D., and Gowda, V.R. (2001). US College Students' Reports of Receiving Health Information on College Campuses. Journal of American College Health, 49(5), 223-228.

Britten, P., Cleveland, L.E., Koegel, K.L., Kuczynski, K.J., and Nickols-Richardson, S.M. (2012). Updated US Department of Agriculture Food Patterns Meet Goals of the 2010 Dietary Guidelines. Journal of the Academy of Nutrition and Dietetics, 112(10), 1648-1655.

Brunson, J.A., Øverup, C.S., Nguyen, M.L., Novak, S.A., and Smith, C.V. (2014). Good Intentions Gone Awry? Effects of Weight-Related Social Control on Health and Well-being. Body Image, 11(1), 1-10.

Brunt, A.R. and Rhee, Y.S. (2008). Obesity and Lifestyle in U.S. College Students Related to Living Arrangements. Appettite, 51(3), 615-621.

Cash, T.F., and Green, G.K. (1986). Body Weight and Body Image Among College Women: Perception, Cognition, and Affect. Journal of Personality Assessment, 50(2), 290-301.

CDC. Behavioral Risk Factor Surveillance System: Prevalence and Trend Data-Overweight and Obesity, U.S. Obesity Trends by State 2010. Available online at http://www.cdc.gov/brfss/

CDC. BMI Index calculator can be accessed at: http://www.cdc.gov/healthyweight/assessing/bmi/index.html

CDC. BRFSS Behavioral Risk Factor Surveillance System: Prevalence and Trend Data-Physical Activity, U.S. Physical Activity Trends by State 2009-2010. Available online at http://www.cdc.gov/brfss/

CDC. MMWR September 2010 State-Specific Trends in Fruit and Vegetable Consumption Among Adults United States, 2000-2009. Available online at http://www.cdc.gov/mmwr/pdf/wk/mm5935.pdf

CDC. Overweight and Obesity Chart for Delaware: http://www.cdc.gov/obesity/stateprograms/fundedstates/delaware.html

Centers for Disease Control and Prevention (CDC) websites: http://www.cdc.gov/obesity/adult/defining.html; http://www.cdc.gov/healthyweight/assessing/bmi/index.html 
Centers for Medicaid and Medicare Services (CMS), Medicaid Statistical Information System (MSIS)

Chang, D.I., Gertel-Rosenberg, A., Drayton, V.L., Schmidt, S., and Angalet, G.B. (2010). A Statewide Strategy to Battle Child Obesity in Delaware. Health Affairs, 29(3), 481-490.

Costin, C. (2013). Your Dieting Daughter: Antidotes Parents Can Provide for Body Dissatisfaction, Excessive Dieting, and Disordered Eating. Routledge.

D’Souza, M.J. and Wang, Q.J. (2012). Inter-institutional Partnerships Propel a Successful Collaborative Undergraduate Degree Program in Chemistry. Journal of College Teaching and Learning, 9, 245-252

D’Souza, M.J., Dwyer, P., Miller, J.M., Drohan, J., and Allison, B.E. (2011). Wesley College Ignites Potential with Undergraduate Student Research Program. Council of Undergraduate Research Quarterly, 32, 41-46

Delaware News Journal, September 6, 2014. Retrieved from: http://www.delawareonline.com/story/news/health/2014/09/05/delawares-obesity-problem/15165337/

Dissen, A.R., Policastro, P., Quick, V., and Byrd-Bredbenner, C. (2011). Interrelationships Among Nutrition Knowledge, Attitudes, Behaviors and Body Satisfaction. Health Education, 111(4), 283-295.

Driskell, J.A., Kim, Y.N., and Goebel, K.J. (2005). Few Differences Found in the Typical Eating and Physical Activity Habits of Lower-Level and Upper-Level University Students. Journal of the American Dietetic Association, 105(5), 798-801.

Ellis, L., and Haman, D. (2004). Population Increases in Obesity Appear to be Partly due to Genetics. Journal of Biosocial Science, 36(05), 547-559.

Fagan, H.B., Diamond, J., Myers, R., and Gill, J.M. (2008). Perception, Intention, and Action in Adolescent Obesity. The Journal of the American Board of Family Medicine, 21(6), 555-561.

Finkelstein, E.A., Fiebelkorn, I.C., and Wang, G. (2004). State-Level Estimates of Annual Medical Expenditures Attributable to Obesity. Obesity Research, 12(1), 18-24.

Gallup Well-Being (2014). Retrieved from: http://www.gallup.com/poll/167642/mississippians-obese-montanansleast-obese.aspx

Grimes, K., Jackson, E.M., and Shorter, A. (2013). A Descriptive Assessment of Fitness, Weight Status \& Health of Delaware State University Students. In International Journal of Exercise Science: Conference Proceedings 9 (1), 29.

Gupta, S. (2014). Obesity and the Prevalence of Diabetes and Diabetes-Related Cardiovascular Comorbidities in Delaware. Delaware Medical Journal, 86(1), 13-20.

Haberman, S., and Luffey, D. (1998). Weighing in College Students' Diet and Exercise Behaviors. Journal of American College Health, 46(4), 189-191.

Hansen, K. (2013). Buddy Up Program Evaluation: Creating an Overall Lifestyle Change. Senior Honors Theses, Paper 340, Eastern Michigan University.

Himes, J.H. (2009). Challenges of Accurately Measuring and Using BMI and Other Indicators of Obesity in Children. Pediatrics, 124(1), S3-S22.

Hoerr, S.L., Bokram, R., Lugo, B., Bivins, T., and Keast, D.R. (2002). Risk for Disordered Eating Relates to Both Gender and Ethnicity for College Students. Journal of the American College of Nutrition, 21(4), 307-314.

James, D., and Bonds, J.R. (2006). Obesity Status and Body Satisfaction: Are There Differences between African American College Females at Black and White Universities? Health Educator, 38(1), 7-14.

Kang, J., Ciecierski, C.C., Malin, E.L., Carroll, A.J., Gidea, M., Craft, L.L., and Hitsman, B. (2014). A Latent Class Analysis of Cancer Risk Behaviors among US College Students. Preventive Medicine, 64, 121-125.

Kravitz, L. (2010). Waist-to-Hip Ratio, Waist Circumference and BMI: What to Use for Health Risk Indication and Why? IDEA Fitness Journal, 7(9), 18-21.

LaCaille, L.J., Dauner, K.N., Krambeer, R.J., and Pedersen, J. (2011). Psychosocial and Environmental Determinants of Eating Behaviors, Physical Activity, and Weight Change Among College Students: A Qualitative Analysis. Journal of American College Health, 59(6), 531-538.

Lessard, L., Williams Leng, S., and Brennan, R. (2013). Consistency of Compliance with Nutrition-Related Regulations among Delaware Child Care Centers. Childhood Obesity, 9(3), 233-239.

Lopez-Jimenez, F. and Miranda, W.R. (2010). Diagnosing Obesity: Beyond BMI. Virtual Mentor, 12(4), 292-298.

MacCann, C., and Roberts, R.D. (2013). Just as Smart but not as Successful: Obese Students Obtain Lower School Grades but Equivalent Test Scores to Non-obese Students. International Journal of Obesity, 37(1), 40-46.

Medical News Today (2013) Retrieved from: http://www.medicalnewstoday.com/articles/262226.php

Morrell, J.S., Reilly, R.A., and Casey, G.B. (2013). Changing Prevalence of Overweight, Obesity and Metabolic Syndrome Criteria Among College Students. The FASEB Journal, 27, 226.3 
Napolitano, M.A., Hayes, S., Bennett, G.G., Ives, A.K., and Foster, G. D. (2013). Using Facebook and Text Messaging to Deliver a Weight Loss Program to College Students. Obesity, 21(1), 25-31.

Ogden, C.L., Carroll, M.D., and Flegal, K.M. (2008). High Body Mass Index for Age among US Children and Adolescents, 2003-2006. JAMA, 299(20), 2401-2405.

Ogden, C.L., Carroll, M.D., Kit, B.K., and Flegal, K.M. (2014). Prevalence of Childhood and Adult Obesity in the United States, 2011-2012. JAMA, 311(8), 806-814.

Puhl, R.M., and Heuer, C.A. (2009). The Stigma of Obesity: A Review and Update. Obesity, 17(5), 941-964.

Raymond, L.A.I. (2013). Just for the Health of It: Facilitators and Barriers to Increasing Physical Activity in Delaware Elementary Schools. Doctoral dissertation, University of Delaware.

Rothman, K. J. (2008). BMI-related Errors in the Measurement of Obesity. International Journal of Obesity, 32, S56-S59.

Sanchez-Villegas, A., Field, A.E., O'Reilly, E.J., Fava, M., Gortmaker, S., Kawachi, I., and Ascherio, A. (2013). Perceived and Actual Obesity in Childhood and Adolescence and Risk of Adult Depression. Journal of Epidemiology and Community Health, 67(1), 81-86.

Sira, N., Pawlak, R. (2010). Prevalence of overweight and obesity, and dieting attitudes among Caucasian and African American college students in Eastern North Carolina: A cross-sectional survey. Nutritional Research Practice, 4(1): 36-42.

Sparling, P.B. (2007). Obesity on Campus. Preventing Chronic Disease, 4(3). Retrieved from: http://www.ncbi.nlm.nih.gov/pmc/articles/PMC1955391/

State Summary DataMart, 2011.

Sweetman, H., Sherretz, K., and Ackerman, C.M. (2007). Public Opinion of Education: Child Obesity and Teacher Recruitment and Retention 2007. University of Delaware Education Research \& Development Center. Retrieved from: http://udspace.udel.edu/handle/19716/3132

Taras, H., and Potts-Datema, W. (2005). Obesity and Student Performance at School. Journal of School Health, 75(8), 291-295.

Torres, S.J., and Nowson, C.A. (2007). Relationship Between Stress, Eating Behavior, and Obesity. Nutrition, 23(11), 887-894.

United States. Department of Health. (1996). Physical Activity and Health: a Report of the Surgeon General. DIANE Publishing.

Wang, Y. and Beydoun, M.A. (2007) The Obesity Epidemic in the United States-Gender, Age, Socioeconomic, Racial/Ethnic, and Geographic Characteristics: A Systematic Review and Meta-Regression Analysis. Epidemiologic Reviews, 29, 6-28.

Wansink, B., and Payne, C.R. (2008). Eating Behavior and Obesity at Chinese Buffets. Obesity, 16(8), 1957-1960.

Wesley College INBRE website: http://www.wesley.edu/academics/grants/inbre.html

Wesley College IRB website: http://www.wesley.edu/academics/programs/institutional-review-board.html

Wesley College website: http://www.wesley.edu/

WHO Global Health Observatory (GHO). (2014). Retrieved from: http://www.who.int/gho/ncd/risk factors/overweight/en/

WHO Waist Circumference and Waist-Hip Ratio. Report of a WHO Consultation. Geneva: World Health Organization, 2011. Retrieved from: http://www.who.int/nutrition/publications/obesity/WHO_report_waistcircumference and waisthip_ratio/en 1

World Health Organization (WHO) Global Database on Body Mass Index website: http://apps.who.int/bmi/index.jsp?introPage=intro_3.html 


\section{APPENDIX A}

What is your present weight

What is your present height

1) How old are you?
a) Under 18
b) $\quad 18-19$
c) 20-21
d) 22
e) Over 22

2) What is your gender?
a) Male
b) Female

3) What academic year are you in?
a) Freshmen
b) Sophomore
c) Junior
d) Senior

4) What is your major?
a) STEM (Science, Math)
b) Health Science (Nursing, Kinesiology)
c) Professional program (Business, Education, Sports Management)
d) Liberal Arts (English, Psychology, History, Philosophy and Religion, Music, Legal Studies, Political Science, Media Arts, American Studies)
e) Other (non-degree student)

5) Are you a member of an on campus athletic team?
a) Yes
b) No

6) Where do you live while attending College?
a) On campus
b) Off campus
c) At home with parents

7) During the week (Monday through Friday) where do you usually eat?
a) Dining hall
b) Wolverine Stop
c) Fast food restaurant such as (McDonald's, Wendy's, Pizza hut, etc.)
d) Parents house
e) Other

8) During the weekend (Saturday and Sunday) where do you usually eat?
a) Dining hall
b) Wolverine Stop
c) Fast food restaurant such as (McDonald's, Wendy's, Pizza hut, etc.)
d) Parents house
e) Other 
9) What is the most typical snack that you consume?
a) Fresh fruit
b) Yogurt
c) Potato chips (or similar fried food)
d) Chocolate or Candy bar
e) Energy bar

10) What kind of bread do you eat most often?
a) $100 \%$ whole wheat
b) Whole grain
c) White, "wheat", Italian, or French
d) Croissant or biscuit
e) I do not eat bread

11) How much fruit do you eat on a daily basis?
a) More than 3 cups
b) 3 cups
c) 2 cups
d) 1 cup
e) $\quad 0$ cups

12) What quantity of vegetables do you eat on a daily basis?
a) More than 3 cups
b) 3 cups
c) 2 cups
d) $\quad 1$ cup
e) $\quad 0$ cups

13) How much milk, cheese, and/or yogurt do you consume on a daily basis?
a) More than 3 cups
b) 3 cups
c) 2 cup
d) $\quad 1$ cup
e) $\quad 0$ cups

14) How many ounces of protein (meat, beans, eggs, nuts, etc.) do you eat on a daily basis? (Hint: 3 ounces of meat, cooked, is approximately the size of a deck of cards)
a) More than $6 \mathrm{oz}$
b) $6 \mathrm{oz}$
c) $\quad 5 \mathrm{oz}$
d) $\quad 4 \mathrm{oz}$
e) $3 \mathrm{oz}$
f) Less than $3 \mathrm{oz}$

15) When you are eating out, do you select your meal choice primarily because of...
a) Taste
b) Attempts to make healthier choices
c) Allergy issues
d) Cost
e) Convenience 
16) What kind of meat do you eat on a regular basis (more than 4 times per week)?
a) beef
b) pork
c) chicken
d) fish
e) processed meat (salami, ham, cold-cuts, hot-dogs, etc.)
f) do not eat meat

17) Since entering College, has your weight
a) Increased
b) Decreased
c) Stayed the same

18) Do you take supplements?
a) Multivitamins
b) Health supplements (fish oil, calcium, etc.)
c) Sport supplements
d) Herbal supplements
e) Energy drinks
f) I do not take any supplements

19) Do you eat breakfast?
a) Daily
b) $\quad 3$ or 4 times a week
c) Once or twice per week
d) Rarely

20) How many legitimate meals do you have each day?
a) One
b) Two
c) Three
d) More than three

21) How often do you exercise for more than 30 minutes at a time?
a) $\quad 0-2$ times per week
b) 3-4 times per week
c) More than 5 times per week

22) Does nutritional information on food labeling in the grocery store, influence your purchases?
a) Yes
b) No

23) Did you get a flu-shot during the past year?
a) Yes
b) No

24) Do you add salt to your food at the table?
a) yes
b) no

25) Have you tried a diet-plan during the past year?
a) yes
b) no 
NOTES 